\title{
Economic Insecurity in the Italian Macro-Regions
}

\author{
Alessandro Gallo ${ }^{1} \&$ Silvia Pacei ${ }^{1}$ \\ ${ }^{1}$ Department of Satistical Sciences, University of Bologna, Bologna, Italy \\ Correspondence: Silvia Pacei, Department of Statistical Sciences, University of Bologna, Bologna, Italy. Tel: \\ 39-051-209-8229. E-mail: silvia.pacei@unibo.it
}

Received: May 31, 2020

doi:10.5539/ijef.v12n8p65
Accepted: July 3, 2020

Online Published: July 10, 2020

URL: https://doi.org/10.5539/ijef.v12n8p65

\begin{abstract}
The interest for economic insecurity has grown constantly over the last decade due to the shock of the latest global crisis that has involved the wealth and behavior of households thus attracting the attention of many authors in contemporary literature. Furthermore, the concept of economic insecurity may be linked to the concept of economic inequality, since an increase in economic inequality may be connected to insecurity and vice-versa. The aim of this article is to measure economic insecurity from 2012 to 2016 in Italy both at national and sub-national level. The methodology applied refers to the economic insecurity index suggested by Bossert et al. (2019) and the data considered are taken from the Survey on Households Income and Wealth carried out by the Bank of Italy. Moreover, this work aims to investigate the possible link between economic insecurity and economic inequalities, measured through the share of wealth owned by the richest $5 \%$ of the population. The main findings show a relevant general increase of economic insecurity in the period between 2012 and 2014, and interesting differences in the variation of economic insecurity at sub-national level. Insecurity appears closely linked to the level of inequality and the trend of inequality in the previous period.
\end{abstract}

Keywords: economic insecurity, wealth, inequality, sub-national analysis, Bank of Italy survey

\section{Introduction}

In the last decade interest for Economic Insecurity has grown constantly due to the economic and financial crisis that took place in 2007 in the US. Even if it was just a marginal topic in literature before 2000, the economic insecurity gained attention of governments and also international organizations even before the global crisis of 2007 (Osberg, 1998). Franklin Roosevelt in 1934, created a special committee called "Cabinet Committee on Economic Security", whose recommendations led to the development of the Social Security Act of 1935, creating a system of social insurance to protect the population from the risk of economic disaster. The Federal Reserve Board's Consultant Committee on Consumer Survey Statistics, after twenty years, recommended gathering some data in order to control the "popular feeling of anxiety and insecurity" (Dominitz \& Manski, 1997). Later on in 1945 it was proclaimed a basic human right from the United Nations: "Everyone has (...) the right to security in the event of unemployment, sickness, disability, widowhood, old age or other loss of livelihood in circumstances beyond his control" (United Nations, 1945, Article 25). Moreover the economic theory suggests the importance of the economic agents' behaviour as one of the main issues in modelling representations of the economic system, and many studies suggest that ordinary agent's life choices are largely influenced by economic insecurity (Hacker, 2019).

Economic insecurity has returned to attract the attention of several authors in contemporary literature, such as Osberg (1998, 2015), Osberg and Sharpe (2002, 2010, 2014), Hacker et al. (2010), Rohde et al. (2014), Bossert and D'Ambrosio $(2013,2016)$ and Bossert et al. (2019), due to the latest global crisis and its worldwide effect on households' wealth and behavior. It is clear how this topic will be investigated even more in these contemporary times, due to the COVID-19 pandemic that will concern the lives of many households and also the economic system on both sides: demand and supply (Fernandes, 2020).

Certainly, the concept of economic insecurity is multifaceted and complex to define. In this paper we refer to the definition provided by Bossert and D'Ambrosio (2013, p. 1018), according to which Economic insecurity represents the "anxiety produced by the possible exposure to adverse economic events and by the anticipation of the difficulty to recover from them". This definition is crucial to clarify the economic past situation and can also be adopted to understand the future. 
Generally, the future is considered the dimension where people feel afraid and insecure because of uncertainty; thus, people try to predict and they begin by using the past experiences (Barrett, 2017). The present resources are important too, indeed if we can rely on a big buffer stock we will be more secure against any kind of misfortune. This is the basis from where Bossert and D'Ambrosio (2013) started the idea of creating this new economic insecurity index based on the past and the present wealth streams of individuals. This idea is quite innovative because the measurement of Economic Insecurity before was mostly based on aggregate measures, like the share of population facing the risk of poverty, as the French-German Ministerial Council has done answering to the report of the Commission on the Measurement of Economic Performance and Social Progress (Stiglitz et al., 2009).

The aim of this paper is to study the distribution of Economic Insecurity in Italy using the strategy recently proposed by Bossert and D'Ambrosio (2016), and considering net wealth as the target variable for the analysis. The choice of maintaining wealth instead of using just disposable income is not random. In this context the net wealth was more desirable to represent economic insecurity due to its composition: real assets plus financial assets, net of financial liabilities. Moreover, the use of net wealth is justified because it is felt that the overall buffer provided by substantial illiquid assets, such as housing equity, plays too strong a role to be neglected. The data have been taken from the Survey on Household Income and Wealth (SHIW) carried out by the Bank of Italy in the years 2012, 2014 and 2016.

Another object of the work is to study the link between economic insecurity and economic inequality. The definition of economic insecurity that we consider, refers to the instability of income and wealth in subsequent periods due to the nature of work, protection from the welfare state, financial and economic crisis, etc., while the measures of economic inequality usually provide a picture of income and wealth gap between individuals in a specific point in time. The two concepts are certainly connected (Ozich et al., 2016) but, to the best of our knowledge, their linkage has not been studied yet.

The study of economic insecurity is particularly interesting for a country like Italy, characterized by a labour market and a housing market with some peculiarities. The labour market reforms introduced in the 1990s with the purpose of making the market more flexible (especially the "Treu package" of 1996), led to a substantial increase in the number of workers with temporary contracts (Fabrizi et al., 2014) thus contributing to the rise of economic insecurity as well. In fact, the Italian labour market is not very dynamic, and temporary workers may experience difficulties in finding a new job rapidly in the event of unemployment. This is true especially for young workers who are more likely to be employed with flexible and temporary contracts. In contrast with this, in Italy workers employed with permanent contracts are well protected and may count on generous unemployment benefits (Banca d'Italia, 2013).

Moreover, the definition of wealth that we use also includes the value of real estate properties that have represented, also during the latest global crisis period, a high proportion of the wealth of the Italians, even if such a value shows large differences between regions and urban or non-urban areas.

In summary the work aims to answer the following questions:

Q1: How has economic insecurity evolved in Italy and in the Italian macro-regions (North, Centre, South and Islands) in the period from 2012 to 2016 ?

Q2: What is the relationship between economic insecurity and economic inequality?

The article is organized as follows. The next Section presents the literature on economic insecurity and the methodology used to compute an adequate index. In Section 3 the data and variable used are described. In Section 4 the results obtained at national and sub-national level from the application to SHIW data are reported. Section 5 compares the distribution of economic insecurity in the Italian macro-regions. Section 6 presents a comparison between economic insecurity and economic inequality. The final section concludes and provides some suggestions for future research.

\section{Literature Review}

\subsection{Economic Insecurity}

The concept of economic insecurity, as already mentioned, is complex and multi-faceted and hence difficult to measure. The first author who tried to measure economic insecurity is Lars Osberg in 1998. He distinguishes between risk and insecurity. He argues that the risk is the cause of economic insecurity, thus it may not be possible to measure "insecurity" objectively, but it may be possible to measure the risk which produces a sense of insecurity. In 2002 Osberg developed, with the collaboration of Andrew Sharpe, an index for measuring well-being, the IEWB (Index of Economic Well-Being). This index is an indicator composed of 4 components: 
"effective per capita consumption flow", "net societal accumulation of stocks of productive resources", "income distribution - poverty and inequality" and "economic insecurity". The insecurity component is measured by examining the most important hazards (job loss and unemployment, illness, family breakup, poverty in old age) assuming that "changes in the subjective level of anxiety about a lack of economic safety are proportional to changes in objective risk" (Osberg \& Sharpe, 2010). Each risk-score is then computed with the percentage of population who face that risk. In 2014, Osberg and Sharpe used the Economic Security component as an economic insecurity measure (IEWB Economic Security Index) to measure the differences in economic insecurity between rich and poor countries, where the rich ones are some OECD countries (Germany, Denmark, Canada, United States) while the poor ones are Vietnam, South-Africa, Messico, Brazil and others.

The advantage of the IEWB Economic Security Index is that it considers economic insecurity stemming from different dimensions, whilst the one proposed by D'Ambrosio and Rohde (2014) relies on just one variable, net wealth. On the other hand, the IEWB Economic Security Index is based on aggregate values, hence it can only provide an aggregate view of the phenomena, whereas the index suggested by D'Ambrosio and Rohde (2014) measures economic insecurity at individual level. It provides a score for each individual through a function that compares the level of individual wealth in a number of previous points in time. This computation is in line with the definition of "insecurity" (Bossert \& D'Ambrosio, 2013) already mentioned in Section 1. Finally, the score obtained at individual level may be summarized to obtain an aggregate measure.

A different approach was proposed by Hacker et al. (2010). They created an individual based index to measure the aggregate economic security called Economic Security Index (ESI) settling a different definition for "insecure". The "insecures" are those people whose available household income decreases by at least 25 per cent from one year to the next, as a result of 3 possible causes: a decrease in household income, an increase in out-of-pocket medical spending or a lack of a consistent disposable wealth to overcome the 2 previous risks (Hacker et al., 2010). Indeed, the first step of computation of the ESI is to define who is insecure, by collecting a dummy variable " $\mathrm{r}$ " that gives 1 when a consumer matches the requirements of being insecure and 0 if not. The final step is a sum of the 1's obtained in the first step weighted with the sampling weights. The result is the insecure proportion of the population expressed as a percentage. The advantages of this approach are that is simple and consistent. It can be easy to understand and sophisticated enough to provide a foundation for further research. This approach is different from that suggested by Osberg, because it is a micro-data-based approach but, instead of giving a score for each individual, like D'Ambrosio and Rohde (2014) do, its aim is to understand who is insecure and who is not. This method brings some disadvantages as, for example, not providing individual scores, it does not allow the study of the "distribution" of insecurity among the individuals.

Another approach is the one proposed by Rohde et al. (2014), who notice that: "the term (economic insecurity) is broadly used to refer to a state of stress or anxiety concerning one's financial future". Rohde et al. (2014) emphasize that this concept is inherently "forward-looking". Like D'Ambrosio and Rohde (2014) they consider data on individuals' past experiences in building a micro-based index, in order to estimate the individual's perception of the future. They emphasize the importance of past volatility, especially the volatility of income rather than wealth (Osberg, 2015). They consider a stream of disposable income and they argue that "households may prefer to accept some slightly lower average income if the new level could be free from fluctuations" (Rohde et al., 2014). This means that a volatile stream is less desirable than a steady one. They calculate an average of income called "Certainly Equivalent (CE) income" that gives the same welfare level as the real stream, which is free to fluctuate. The more an $x_{i}$ value differs from the CE income the higher the insecurity will be.

This approach is the most similar to the one by D'Ambrosio and Rohde (2014) but as Obserg (2015) noticed, behind this measure is the assumption that a downward deviation from a descending trend is assumed equivalent to a downward deviation of the same size from an ascending trend, and this can be questioned. The measure proposed by Bossert and D'Ambrosio (2013) targeted this issue by differentiating these two situations and giving to the first a higher insecurity score.

Another important issue regards the choice of the variable to consider evaluating economic insecurity. This choice is by no means crucial and has few consequences to consider. The idea of using just one variable is clearly a simplification to describe a multifaceted issue such as economic insecurity. Indeed, in the literature there are several examples of economists trying to model economic phenomena using simpler and more tractable representations of the real world (Bossert \& D'Ambrosio, 2013). The concept of wealth is often used in research on poverty, inequalities and deprivation, maybe switched with disposable income when information on wealth is not available (see for example Brzozowski et al., 2010). In this work we consider wealth instead of income, because it also includes the net patrimony such as real estate proprieties. Indeed, for example, in a critical 
situation of economic insecurity one could easily think of selling some goods (which are part of the patrimony) to overcome an important economic hardship. In this context in fact wealth is assumed to be everything that can help the individual in facing unexpected negative shocks, including "entitlements" on family, government or friends in the sense of Sen (1976).

\subsection{The Economic Insecurity Index}

For characterizing the economic insecurity index Bossert and D'Ambrosio $(2013,2016)$ use an axiomatic approach. This decision is shared with many other contributions in the context of modelling an index in economics and in social sciences, like for example Arrow (1951) and Sen (1970). The aim of this approach is to create some proprieties that a measure in this context should satisfy and then develop the only class of measure that can respect those axioms (Thomson, 2001).

Considering a $\mathbb{R}_{(T)}$ a $(T+1)$-dimensional Euclidean space and the vector $(T, \ldots, 0)$, where $T$ is the number of past periods (lags) taken into account and 0 represents the current period, the economic insecurity measure is defined as a function $I=\left\langle I^{T}\right\rangle_{T \in N}$ that for every $T \in \mathbb{N}$, gives $I^{T}: \mathbb{R}^{(T)} \rightarrow \mathbb{R}$. Moreover, considering the individual net wealth stream vector $\left(w_{1}, w_{2}, \ldots, w_{T}\right) \in \mathbb{R}^{(T)}$, the economic insecurity index $I$, should produce a score for each stream that will be attached to each individual.

The index suggested by Bossert and D'Ambrosio (2016) respects the following axioms: Gain-loss monotonicity; Proximity monotonicity; Resources-variation monotonicity; Homogeneity; Translation invariance; Quasilinearity; Stationarity; Loss priority.

The first one guarantees that a lower level of insecurity is attached to a situation where there is a gain in the earliest period compared to a situation where there is no change. The second one assures that a loss (or a gain) in the past has less weight that a loss (or a gain) in the present, thus a loss perceived, for example, in $t=4$ has less weight than a loss perceived in $t=3$. The third monotonicity propriety is an extension of the two previous ones, and means that a movement of the stream of the type "first down and then up", which means a loss and then straight forward a gain, is considered as a decrease in the insecurity score, while the opposite is true for a "first up then down movement". Therefore, a movement like "first down and then up" gives less decrease in the insecurity score if it is done in period 4 than if it is done in period 3 (one period more in the past), and clearly the opposite is true in the case of a "first up then down move".

The next two proprieties are two classic proprieties used in the axiomatic approaches (Thomson, 2001), also used in formulation of indexes in the poverty and inequality context. The first one is the "Homogeneity" and it basically guarantees that, if the net wealth stream is multiplied by a constant, the index score will also be multiplied by that constant. The second one is the "Translation invariance" and it requires that if the same amount is added to each net wealth level of the stream, the insecurity score resulting remains the same.

The "Quasilinearity" propriety is an algebraical propriety ensuring that, considering the net wealth stream $w \in \mathbb{R}^{(T)}$, the insecurity score $I^{T}(w)$ attached to this stream can be expressed as a function of the differences $w_{T}-w_{T-1}$ considering the $T-1$ most recent resource levels.

The "Stationarity" propriety guarantees that if two net wealth streams $p$ and $q$ are shifted of $r$ periods in the past and in the additional periods $s$ are assigned $s$ net wealth levels, the comparison between the two streams remains unchanged.

Finally, the "Loss priority" guarantees that in a given period a loss has more weight than a gain of the same magnitude, ceteris paribus.

The index that satisfies all these proprieties proposed by Bossert et al. (2019) is:

$$
I^{T}(w)=l_{0} \sum_{\substack{t \in\{1, \ldots, T\} \\ w_{t}>w_{t-1}}} \delta^{t-1}\left(w_{t}-w_{t-1}\right)+g_{0} \sum_{\substack{t \in\{1, \ldots, T\}: \\ w_{t}<w_{t-1}}} \delta^{t-1}\left(w_{t}-w_{t-1}\right)
$$

where $l_{0}, g_{0} \in \mathbb{R}_{++}$and $\delta \in\left(0, g_{0} / l_{0}\right)$, such that $l_{0}>g_{0}$ and for all $T \in \mathbb{N}$ and for all $w \in \mathbb{R}^{(T)}$. Coefficients $l_{0}, g_{0}$ are, respectively, the coefficient for the losses and the coefficient for the gains, chosen such as $l_{0}>g_{0}$ to respect the "Loss priority" propriety. $w_{t}$ is the net wealth level in time $t$, and $\delta$ is the discount factor which must be equal for gains and losses. A higher value for the discount factor ensures a higher weight attached to the past.

The index is clearly composed involving a sort of "if". Indeed, all the periods where a loss is perceived are captured from the first summation, and all the periods where a gain is perceived are captured from the second summation.

Following Bossert et al. (2019), in this study the values chosen for the parameters are $l_{0}=1, g_{o}=15 / 16$ and 
$\delta=0.9$. However, the authors notice that the results are almost robust with respect to different choices for these values.

\section{Data}

For the purpose of this analysis, we use data taken from the Survey of Household's Income and Wealth (SHIW) carried out by the Bank of Italy. The survey waves corresponding to three different years 2012, 2014, 2016 are considered, and the economic insecurity index is computed by matching observations for the 4 previous waves. Doing that, three different datasets have been obtained (the first dataset considers data from 2004 to 2012, the second from 2006 to 2014 and the third from 2008 to 2016). The outcome variable is the households' net wealth, computed as the sum of real assets (property, businesses and valuables) and financial assets (deposits, government securities, shares, etc.) net of financial liabilities (mortgage loans and other debts) (Banca d'Italia, 2013).

The observations considered in each dataset are the households participating in the survey in the year of interest and the previous waves necessary to calculate the index ( 5 years). It is necessary to achieve a balanced panel to compute the indicator of interest, so any household with missing observations is dropped, while zero and negative observations are included. The wealth stocks are then discounted to remove inflation, considering 2010 as the base year, and then it is equalized in proportion to the number of people in the household for each wave by dividing each household wealth stock of each year by the equivalent size obtained from the OECD modified equivalence scale. The same equivalent wealth stock is considered for each member of a household in the selected year, as the statistical unit used in the analysis is the individual. After that, the distributions are trimmed: the top and bottom 1 per cent of the wealth distribution are dropped as considered outliers, as they are clearly different from the rest of the sample and have the effect of biasing results. In this way, three panel datasets with 5232, 4449 and 4126 observations are obtained for 2012, 2014 and 2016. Longitudinal sampling weights are used through all our analysis.

\section{Economic Insecurity in the Italian Macro-Regions}

The weighted mean and median of the individual economic insecurity index calculated using (1) are computed for the Italian macro-regions and for the whole Country (Table 1).

Regarding the whole Country, the mean obtained in 2014 is 9 times bigger than the one obtained for 2012, then there is a small decrease of about $9 \%$ from 2014 to 2016, therefore in 2016 it remains considerably higher than the value obtained for 2012. The median also drastically increases between 2012 and 2014 (almost 10 times higher). This indicates a right shift of the distribution through a more insecure "stage".

Table 1. Economic insecurity index descriptive statistics at national and macro-regional level

\begin{tabular}{lccc}
\hline & 2012 & 2014 & 2016 \\
\hline Italy & & & 20293.22 \\
Mean & 2450.69 & 22225.11 & 6354.63 \\
Median & 675.87 & 6702.06 & 20388.43 \\
\hline North & & & 13500.34 \\
Mean & 4119.51 & 27871.24 & 39478.29 \\
Median & 3510.74 & 9338.26 & 16223.04 \\
\hline Centre & & & 11826.56 \\
Mean & -6163.74 & 39346.41 & 552.32 \\
\hline Median & -861.33 & 16716.53 & \\
Meath and Islands & & & 11162.10 \\
Median & 5375.41 & 2320.76 & \\
\hline
\end{tabular}

Source: Our elaboration on SHIW data.

This relevant change in the average of the economic insecurity index can be explained by the variation over time of the net wealth. A decrease of $11 \%$ of the average net wealth in real terms was observed in 2014, compared to the 2012 level (Banca d'Italia, 2015). This dramatic decline is probably due to a strong drop in the net wealth of the better-off households, which amounted to $15 \%$ of the whole wealth distribution. Indeed, according to the Bank of Italy (2015), the richest 5\% of households in 2014 owned a mean wealth of $€ 1,300,000$ and accounted for over $30 \%$ of total wealth. 
Considering that the net wealth is also composed of real assets (propriety, businesses and valuables), the dramatic decrease in the net wealth of the better off households is largely due to the fall in property values, which reflects a broader deterioration of real estate prices (Banca d'Italia, 2015). In fact, the value of real estate represents the largest share of the total net wealth of the households in all the twenty quintiles of the distribution of the net wealth, except in the lowest ones (Banca d'Italia, 2015).

The crisis that took place in 2012 had a strong impact on the Italian real estate market, causing a decrease in the sales of about $29.6 \%$ in the last quarter of the year. According to the Italian Revenue Agency, this decline of the real estate market was also due to the credit situation in those years: the rise of interest rates influenced the market causing a reduction of loans for buying houses by $38.6 \%$ (Dipartimento delle Finanze e Agenzia del Territorio, 2012). This drop in the real estate market is a possible cause of the important right shift of the distribution of the economic insecurity index, and it is also confirmed by the findings obtained at subnational levels for the three Italian macro-regions. For all the three macro-regions an important increase in the weighted mean can be observed from 2012 to 2014. However, the growth greatly differs among the three macro-regions: it is larger in the Centre, where it reaches around 600 percentage points (from -6,164 to 39,346) while it is smaller in the South and Islands, where it is approximately $108 \%$ (from 5,375 to 11,162). The variation of the weighted mean is less uniform from 2014 to 2016 in the three areas, as in the Centre and the South the mean shows a little increase, respectively $0.3 \%$ for the Centre and $6 \%$ for the South, while it decreases in the North by $26 \%$ (in line with what was observed at national level).

As one would expect the total variation obtained in the North is similar to those observed at national level, while in the South it seems more stable in both years and in the Centre the fluctuation is way more evident. This can be explained by the composition of the net wealth in the different macro-regions. Indeed, the composition and the value of the real estate patrimony is quite different considering the three different Italian macro-regions, as emerges from the Italian Revenue Agency description of the estimated value of the real estate patrimony in the Italian macro-regions reported in Table 2 (Dipartimento delle Finanze e Agenzia del Territorio, 2012).

As one can see from Table 2, the mean value of the sum of all the components of the real estate owned by the households is larger in the Centre than in the South and Islands (approximately $+35 \%$ ) and in the North $(+10.62 \%)$. This can explain the greater variation over time registered among the Central region compared to the South and Islands. The real estate value fall in 2012 represents a reason for the strong decline of the richest quintile of the net wealth distribution, as registered by Bank of Italy in 2014, and this decline is in turn responsible for the sensible growth of the economic insecurity index in 2014.

Table 2. Distribution of real estate patrimony in the Italian macro-regions.

\begin{tabular}{lrrrr}
\hline & North & Centre & South and Islands & Italy \\
\hline Cadastral Category & Mean & Mean & Mean & Mean \\
\hline Houses & 89.705 & 101.625 & 72.224 & 87.901 \\
Offices and Private Studios & 110.407 & 130.480 & 86.582 & 109.632 \\
Shops and boutiques & 68.589 & 82.538 & 64.362 & 70.652 \\
Main dwelling appliances & 15.237 & 16.739 & 19.003 & 16.315 \\
Buildings for collective use & 39.326 & 31.778 & 65.718 & 42.735 \\
Other appliances & 40.967 & 55.284 & 39.503 & 43.931 \\
Buildings for productive use & 185.177 & 195.569 & 219.212 & 194.235 \\
Total & 109.663 & 121.315 & 89.919 & 107.171 \\
\hline
\end{tabular}

Source: Dipartimento delle Finanze e Agenzia del Territorio (2012, p. 108).

To evaluate the significance of the variation over time of the results obtained on average for the economic insecurity index, the confidence intervals for the estimates the means of the economic insecurity index for the 3 years are estimated. To this purpose, the standard errors of the estimates are obtained by considering the same resampling method used by the Bank of Italy for the computation of the standard errors of the estimates in the context of the SHIW (Faiella, 2008), that is the Jack-knife method.

In order to obtain reliable estimates of the standard errors, the sampling strategy used to resample the observations should be as close as possible to the sampling method adopted to select the original sample. In the SHIW survey, a two-stage sampling strategy with stratification of the primary sampling units is adopted. In the first stage, municipalities are selected according to a stratified sample while, in the second stage, households are randomly selected from the municipalities included in the first stage. Nevertheless, the information on the 
primary sampling units, is not available in SHIW datasets due to privacy reasons. Therefore, we assume a simpler sampling strategy, in which households are selected form a single stage stratified sample. Strata are defined by cross-classifying the households according to the same variables considered in the real sampling scheme: the demographical size of the municipality where the households are resident (5 categories), and the region, at NUTS2 level (20 categories). For a deeper discussion about the sampling method used in the SHIW see Faiella (2008).

The Jack-knife resampling method we used includes the following steps. 1. Households are grouped into 100 strata. 2. A simple random sampling is applied to the first stratum to sample half of the households. 3. For the observations contained in that sub-sample, the sampling weights are doubled and multiplied by the number of components of the family (Faiella, 2008). 4. The weighted mean of the economic insecurity index for the whole dataset is now computed, considering the new weights for the sub-sample and normal weights for the rest of the dataset (the not-sampled half of the first stratum is excluded). 5. The second half of the first stratum is now considered: the sampling weights are doubled and multiplied by the number of components of the household. 6 . Again, the weighted mean is computed as in step 4 but without considering the half stratum used before. 7 . The process from step 1 to step 6 is repeated for all the strata in the dataset. 8. The Jack-knife variance is computed with this formula (Wolter, 1985):

$$
V_{J K}=\frac{1}{A(A-1)} \sum_{i=1}^{162}\left(\bar{I}_{i}-\overline{I_{J K}}\right)^{2}
$$

where $V_{J K}$ is the variance obtained using the Jack-knife method, $A$ is the total number of strata, $\overline{I_{J K}}$ represents the arithmetic mean of the Jack-knife means of the Insecurity Index obtained as already described and $\bar{I}_{i}$ is the mean in the $i . t h$ stratum.

The confidence intervals obtained at $95 \%$ level are reported in Table 3.

Table 3. 95\% Confidence intervals for the mean of economic insecurity index at national level

\begin{tabular}{lrrr}
\hline & 2012 & 2014 & 2016 \\
\hline Std. Deviation & 271.07 & 224.27 & 212.37 \\
$95 \%$ Conf. Interval & {$[1919.39 ; 2981.99]$} & {$[21785.53 ; 22664.68]$} & {$[19876.98 ; 20709.46]$} \\
\hline
\end{tabular}

Source: Our elaboration on SHIW data.

Considering the high number of observations in the three original samples (respectively 5233 for 2012, 4450 for 2014 and 4127 for 2016), the estimates obtained are very accurate even if the accuracy appears substantially reduced in the 2012 case. The confidence intervals obtained for the three years are considerably far from each other, thus ensuring the significance of the differences observed in the mean of the economic insecurity index over time.

\section{The Distribution of Economic Insecurity}

To shed further light on the significant right shift of the whole distribution observed from 2012 to 2014, the distribution of the economic insecurity index is estimated following a non-parametric approach based on a Kernel density estimation. Following Silverman (1986, pag. 14) we consider the Kernel density estimator which in our context can be defined as:

$$
f(I)=\frac{1}{n h} \sum_{k=1}^{n} \operatorname{GPDF}\left(\frac{i-I_{k}}{h}\right)
$$

where $f(I)$ is the probability density function of the economic insecurity index, $I_{k}$ is the Economic Insecurity for the $k$ observation $(k=1, \ldots, n), n$ is the sample size and GPDF is the Gaussian Probability Density Function, used as a Kernel in this context, and $h$ is the selected bandwidth. Regarding the choice of the bandwidth, we follow the rule suggested by Silverman (1986):

$$
\hat{h}^{\text {opt }}=0,9 \min \left(\sigma ; \frac{\widehat{q_{3}}-\widehat{q_{1}}}{1,349}\right) n^{-1 / 5} \text {. }
$$

In our application the bandwidth is always calculated using the interquartile range as it always results lower than the standard deviation for all the distributions considered.

The densities estimated at national and macro-regional level are reported in Figure 1, while the corresponding quartiles, means and skewness indices are reported in Table 4. The skewness of the kernel densities is measured using the Medcouple statistic, that is defined as a scaled median difference of the left and right part of the distribution, and assumes values in the interval $[0,1]$. In the graph, the means obtained for each year are also pointed. 
At national level, the right shift of the distribution from 2012 to 2014 is confirmed by the shape of the estimated densities and their quartiles, while the shift is much less evident from 2014 to 2016 . Observing the median and the mean, in fact, they are closer in 2014 and 2016 but both much higher compared to the 2012 levels. The 2012 distribution appears even more symmetric then the other two, for which the right tails appear heavier than the left ones. This is also confirmed by the index of skewness (Table 4) that is close to 0 in 2012, indicating an approximately symmetric distribution, while it grows to 0.30 in 2014 and 0.35 in 2016, indicating an increased number of very insecure individuals with respect to 2012. It is interesting to note the 4 "bumps" of the distribution of 2016, on the right side of the plot, which give more weight to the right tail; these bumps explain the increase of the insecurity in the third quartile compared to 2012. One possible explanation to this phenomenon can be given by the variation of the net wealth on average between these points in time already discussed in Section 4. The shock registered in 2014 moved the observations to the most extreme scores while, in 2016, the little gain obtained by the smaller reduction of the average wealth moved the observations to fewer extreme scores.
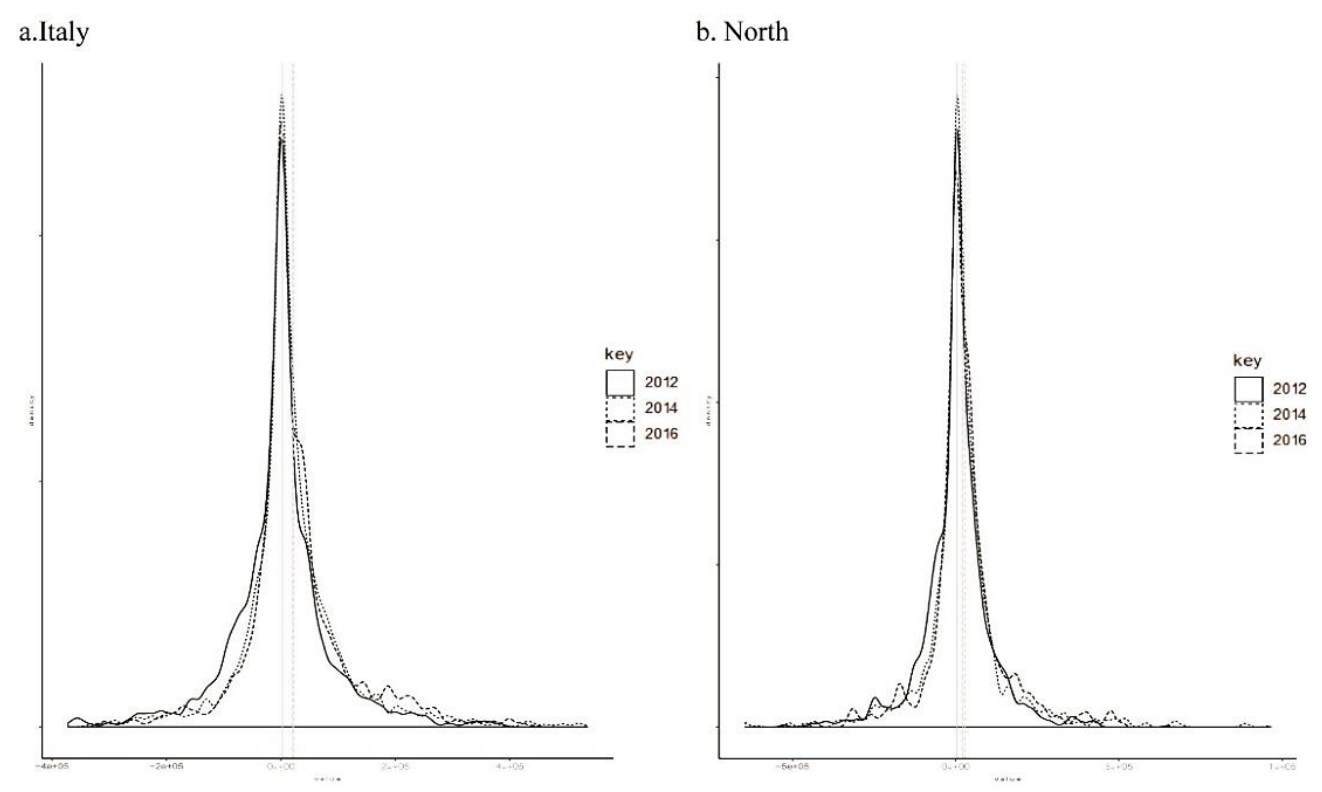

c. Centre

d. South and Islands
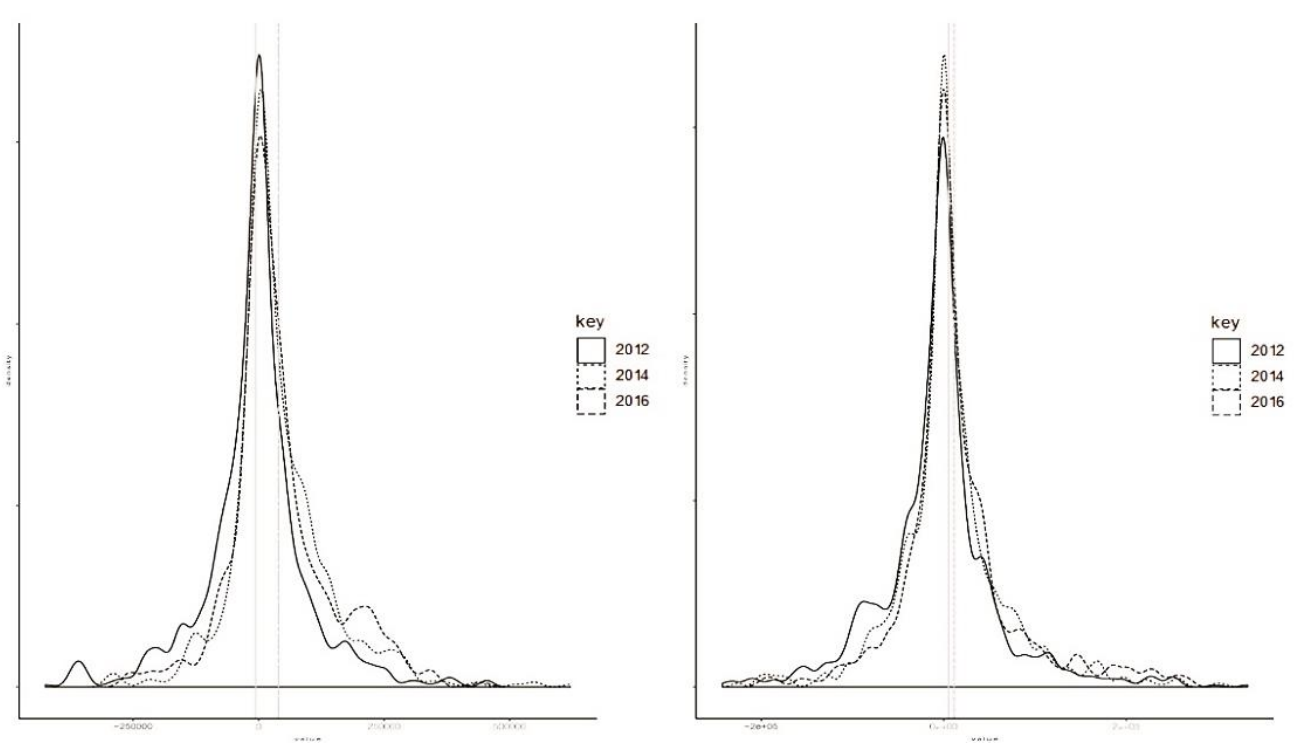

Figure 1. Estimated density distributions of Economic insecurity at national and macro-regional level. (the grey solid and dashed lines represents the means)

Source: Our elaboration on SHIW data. 
Table 4. Quartiles, mean and skewness of the Kernel Densities estimated for Economic Insecurity at national and macro-regional level

\begin{tabular}{lccccc}
\hline YEAR and AREA & \multicolumn{7}{c}{ Quartiles } & Mean & Medcouple \\
\hline 2012 Italy & $25 \%$ & $50 \%$ & $75 \%$ & -0.0449 \\
2014 Italy & -33682.20 & 675.88 & 30950.95 & 2450.69 & 0.3015 \\
2016 Italy & -12758.53 & 6702.07 & 45355.13 & 22225.11 & 0.3483 \\
2012 North & -14403.46 & 6354.63 & 45272.50 & 20293.22 & 0.0673 \\
2014 North & -34193.59 & 3510.74 & 43242.85 & 4119.51 & 0.2430 \\
2016 North & -12970.93 & 9338.22 & 48000.70 & 27871.24 & 0.2651 \\
2012 Centre & -15023.58 & 13500.34 & 60355.76 & 20388.43 & -0.1417 \\
2014 Centre & -43025.99 & -861.33 & 39507.87 & -6163.73 & 0.3496 \\
2016 Centre & -3578.62 & 16716.53 & 81848.84 & 39346.41 & 0.2649 \\
2012 South and Islands & -5863.54 & 16223.04 & 62843.23 & 39478.28 & -0.1536 \\
2014 South and Islands & -27968.56 & -1797.00 & 19738.78 & 5375.40 & 0.2295 \\
2016 South and Islands & -13765.04 & 2320.76 & 30384.08 & 11162.09 & 0.3471 \\
\hline
\end{tabular}

Source: Our elaboration on SHIW data.

At subnational level (Figure 1b, 1c, 1d and Table 4) it is possible to observe in all the macro-regions the same right shift observed at national level from 2012 to 2014. Coherently with what was observed at national level, at macro-region level the most relevant change is from 2012 to 2014, while the change is less evident from 2014 to 2016. The entity of the right shift is different among the different macro-regions. The macro-region with the biggest increase is the Centre, for which the median of the estimated distribution goes from -861 to 16717, while the smallest increment is observed for the South and Islands, from which the median of the distribution goes from -1797 in 2012 to 2321 in 2014.

In the distributions estimated for all the macro-regions it is possible to note the more pronounced tendency, in the Centre, of gaining weight on the right tail from 2012 to 2014, and then gaining a bit of weight on the left tail from 2014 to 2016. The measure of skewness obtained for the macro-regional level enables us to better understand the variations that take place on the tails of the distributions. In all the macro-regions the distribution becomes positive skewed from 2014. However, while in the North it is almost symmetric in 2012 and becomes positive skewed in 2014 (as observed at national level), in the Centre and South and Islands the distribution changes from a slight negative skewed in 2012 to positive skewed in 2014 and 2016, with the difference that in the Centre the asymmetry is more pronounced in 2014 than in 2016 while the opposite occurs in the South and Islands.

\section{Economic Insecurity and Inequality}

The concept of economic insecurity may be connected with that of economic inequality, since the increase in inequality may be linked to that in insecurity and vice-versa. To explore the link between the two phenomena, we compare the economic insecurity index obtained for the three years considered, to the index of inequality given by the share of wealth owned by the richest $5 \%$ of the population. This simple indicator can be considered a valid measure for the inequality of a society as it takes both the existence of very high incomes and assets, and the number of people actually gratified by these amounts into account (Piketty, 2014). Moreover, economists particularly concerned with inequality (Atkinson et al., 2011; Piketty, 2014) support the use of indicators referred to percentiles greater than 90th one, as inequalities can be very high and very interesting to study in that part of the wealth distribution.

For computing the percentage of wealth owned by the richest 5\%, data are taken from the same survey as for the economic insecurity index, the SHIW, but a different set of statistical units is used: all the observations contained in the dataset for each different year are considered, as the index is substantially cross-section. Then we use the same variable, the equalized net wealth, used to calculate the economic inequality index. Results obtained at national and macro-regional level, for the period 2004-2016 are reported in Figure 2. We report results obtained also for previous years with respect to the years targeted for economic insecurity $(2012,2014$ and 2016) because, the economic insecurity index also takes the wealth owned by the individual in four previous points in time into account. A very similar Figure is obtained if considering the richest $10 \%$ of the population instead of the top 5\%.

First of all, it is possible to observe that the most relevant variations in inequality took place from 2010 to 2014 , with some differences between macro-regions. If we compare these trends with the trends over the last three 
points in time of the mean of economic insecurity index already reported in Table 1 (Figure 3), we can have an idea on how the insecurity level today can depend on the inequality that has occurred in previous periods.

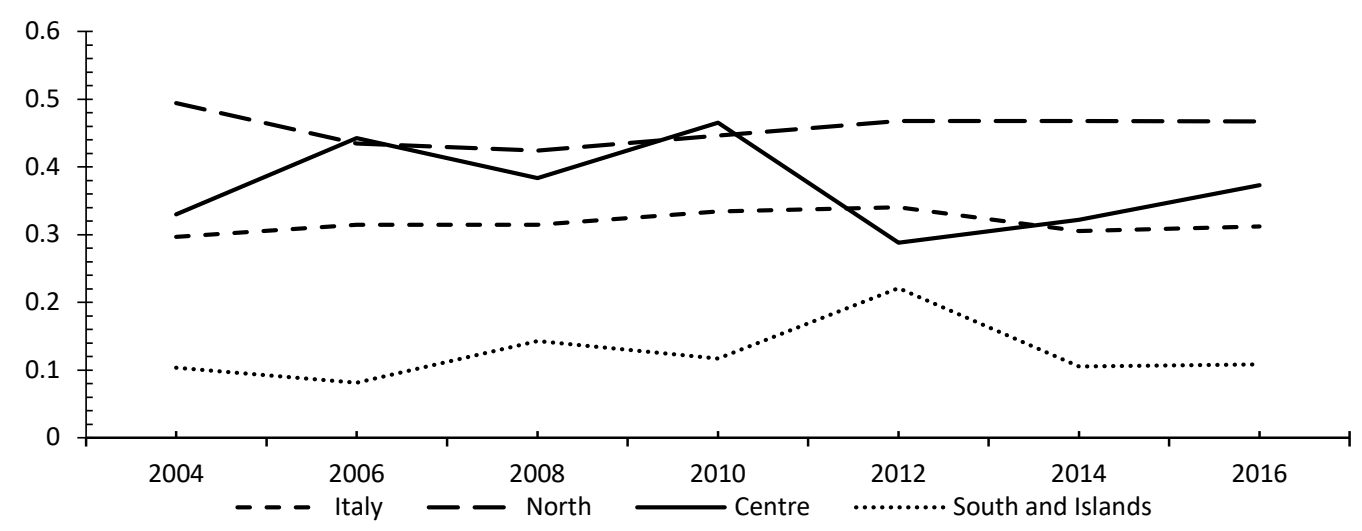

Figure 2. Top 5\% wealth percentage in Italy and Italian macro-regions

Source: Our elaboration on SHIW data.

At national level, the increase in insecurity observed between 2012 and 2014 can be linked to the growth of the inequality occurred in the previous periods, in particular since 2008 , that is certainly connected to the global economic crisis. The trends observed for inequality and insecurity in the North, the most populated Italian macro-region, are very similar to those observed at national level: the inequality slowly increased over time, and the insecurity observed in the last three points in time rapidly increases, as already observed, in 2014 and maintains a high value in 2016 .

Different trends can be observed in the South and Islands and in the Centre. In the South and Islands inequality is much lower than in the North and in the Centre, and its growth is delayed with respect to the North and the Centre. In the South and Islands inequality emerges in a more evident way from 2010 e 2012. Economic insecurity is on average much lower in the South and Islands than in the North and in the Centre, accordingly to what was observed for inequality. The insecurity increment between 2012 and 2014 is definitely weakened in the South and Islands with respect to other macro-regions. The Centre shows a trend in inequality that is completely different from that observed for the North and the South and Island. Inequality in the Centre grows from 2008 and 2010, then it reduces from 2010 e 2012, and then it grows again in subsequent years. Insecurity in the Centre shows the highest increase among the macro-regions from 2012 to 2014.

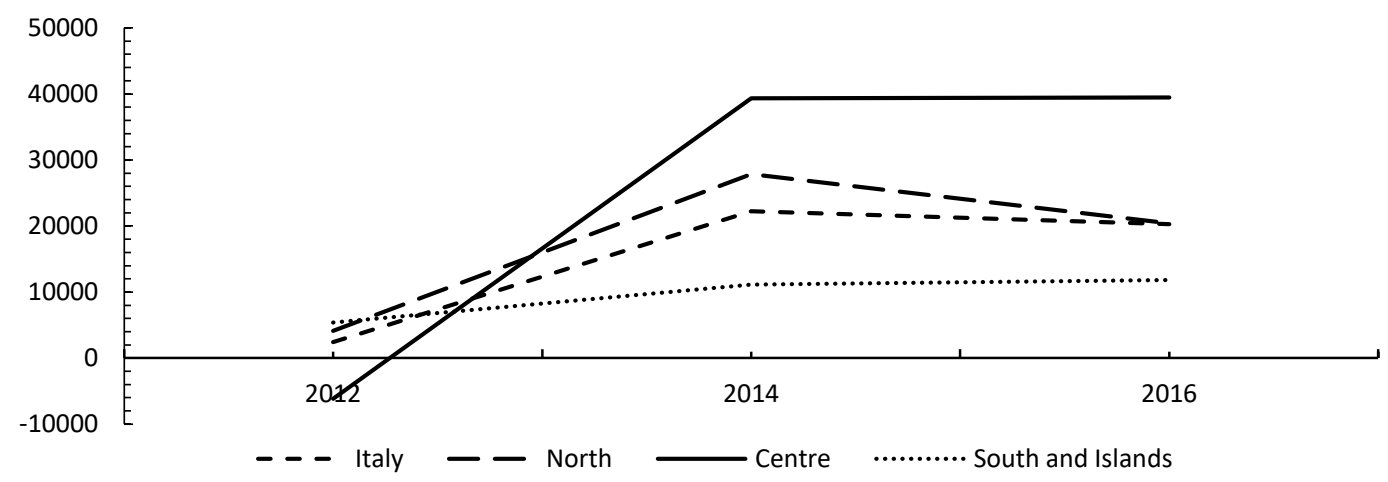

Figure 3. Mean of the economic insecurity index in Italy and Italian macro-regions

Source: Our elaboration on SHIW data.

This phenomenon can be a consequence of the fall of real estate values which causes a drop in the net wealth and has evident consequences on the wealth of the richest $5 \%$ of the population. This shock (the fall of real estate prices) leads to a decrease in inequality from 2010 to 2012, and then to an increase in economic insecurity from 2012 to 2014 (see Section 4) due to the variations in wealth occurred in the previous years. 


\section{Conclusions}

This work studies the distribution of economic insecurity in Italy and contributes to the literature in two substantial ways. First, it assesses economic insecurity not only at national level but also at sub-national level. One of the most important results is the relevant right shift of the economic insecurity index density distribution detected in the period between 2012 and 2014 at national and macro-regional level. The increase of insecurity is particularly relevant in the Centre of Italy. One explanation of this major growth in insecurity is the nature of the target variable adopted for the analysis, net wealth. The most important part of the composition of net wealth are real assets, which are mostly given by the propriety values (Banca d'Italia, 2015). Therefore, the fall of the real estate value in 2012 represents a reason for the strong decline of the richest quintile of the net wealth distribution and the significant decrease in the net wealth mean. The decline of the wealth mean in turn affected Economic Insecurity, causing the observed significant increase in the insecurity Index.

Secondly, this study explores the relationship between economic insecurity and inequality. According to the results obtained for the whole Country and macro-regions, insecurity is closely linked to the level of inequality and the trend of inequality in the previous period. In fact, while in the North the increment in insecurity observed between 2012 and 2014 can be linked to the growth of the inequality which occurred in the previous periods, in the South the economic insecurity, as well as inequality, are on average much lower than in the rest of the Country. In the Centre the very high increase in insecurity from 2012 to 2014 can be connected to the more evident variations in inequality observed in the previous period. However, to study the relationship between the two phenomena in more depth, it would be necessary to have a panel in which the same individuals are observed for a greater number of waves, so that longer time series can be compared.

Finally, this empirical work paves the way for further research regarding the many possible implications of economic insecurity. For example, past research clearly demonstrated that there are significant gender implications of insecurity, as women are more likely to be insecure over employment. Moreover, insecurity is recognized to have a negative impact on the mental health of workers, that may in turn affect their performance at work. Workers, who do not trust the possibility to improve their economic status after a crisis, are more likely to suffer from anxiety and depression. Another worrying consequence concerns the effect on children's outcome, as insecurity may also lead to under-investment in the education of children and increase barriers to socio-economic mobility between generations.

\section{References}

Arrow, K. J. (1951). Social Choice and Individual Values. New York: John Wiley \& Sons.

Atkinson, A. B., Piketty, T., \& Saez, E. (2011). Top Incomes in the Long Run of History. Journal of Economic Literature, 49, 3-71. https://doi.org/10.1257/jel.49.1.3.

Banca d'Italia. (2013). La Ricchezza delle famiglie italiane 2012. Supplementi al Bollettino Statistico, $n$. 65.

Banca d'Italia. (2015). La Ricchezza delle famiglie italiane 2014. Supplementi al Bollettino Statistico, n. 69.

Barrett, L. F. (2017). How emotions are made: The secret life of the brain. Houghton Mifflin Harcourt.

Bossert, W. \& D'Ambrosio C. (2016). Economic insecurity and variations in resources. Working Papers 422, ECINEQ, Society for the Study of Economic Inequality.

Bossert, W., \& D'Ambrosio, C. (2013). Measuring Economic Insecurity. International Economic Review, 54, 1017-1030. https://doi.org/10.1111/iere.12026.

Bossert, W., Clark, A. E., D'Ambrosio, C., \& Lepinteur, A. (2019). Economic Insecurity and the Rise of the Right. Centre for Economic Performance (CEP), Discussion Papers No. 1659.

Brzozowski, M., Gervais, M., Klein, P., \& Suzuki, M. (2010). Consumption, Income, and Wealth Inequality in Canada. Review of Economic Dynamics, 13, 52-75. https://doi.org/10.1016/j.red.2009.10.006.

D'Ambrosio, C., \& Rohde, N. (2014). The distribution of economic insecurity: Italy and the U.S. over the Great Recession. The Review of Income and Wealth, 60, S33-S52. https://doi.org/10.1111/roiw.12039.

Dipartimento delle Finanze e Agenzia del Territorio. (2012). Gli immobili in italia. Ricchezza, Reddito e Fiscalità Immobiliare.

Dominitz, J., \& Manski, C. F. (1997). Perceptions of Economic Insecurity: Evidence from the Survey of Economic Expectations. The Public Opinion Quarterly, 61, 261-287. https://doi.org/10.1086/297795.

Fabrizi, E., Ferrante M. R., \& Pacei S. (2014). A Micro-Econometric Analysis of the Antipoverty Effect of Social Cash Transfers in Italy. The Review of Income and Wealth, 60, 323-348. https://doi.org/10.1111/roiw.12048. 
Faiella, I. (2008). Accounting for sampling design in the SHIW. Bank of Italy, Working Paper.

Fernandes, N. (2020). Economic effects of coronavirus outbreak (COVID-19) on the world economy. Preliminary working paper, Available at SSRN 3557504: http://dx.doi.org/10.2139/ssrn.3557504.

Hacker, J. S. (2019). The great risk shift: The new economic insecurity and the decline of the American dream. New York: Oxford University Press.

Hacker, J. S., Huber, G. A., Rehm, P., Schlesinger, M., \& Valletta, R. (2010). Economic Security at Risk. Findings from the Economic Security Index. The Rockefeller Foundation.

Osberg, L. (1998). Economic Insecurity. Social Policy Research Centre, University of New South Wales, Discussion Paper No. 88.

Osberg, L. (2015). How Should One Measure Economic Insecurity? OECD Publishing, OECD Statistics Working Papers, No. 2015/0.

Osberg, L., \& Sharpe, A. (2002). An Index of Economic Weil-Being for Selected OECD Countries. The Review of Income and Wealth, 48, 291-316. https://doi.org/10.1111/1475-4991.00056.

Osberg, L., \& Sharpe, A. (2010). How are we doing? The Index of Economic Well-Being. Challenge, 53, 25-42. https://doi.org/10.2753/0577-5132530402.

Osberg, L., \& Sharpe, A. (2014). Measuring Economic Insecurity in Rich and Poor Nations. The Review of Income and Wealth, 60, 53-76. https://doi.org/10.1111/roiw.12114.

Ozich, C., Lambert, M., \& Harvey, K. (2016). Inequality and Insecurity. Responding to the Challenge of Precarious Work. Australian Institute of Employment Rights, Discussion Paper.

Piketty, T. (2014). Capital in the Twenty-First Century. Cambridge, MA: The Belknap Press. https://doi.org/10.4159/9780674369542.

Rohde, N., Tang, K. K., \& Rao, D. S. P. (2014). Distributional Characteristics of Income Insecurity in the US, Germany and Britain. The Review of Income and Wealth, 60, 159-176. https://doi.org/10.1111/roiw.12089.

Sen, A. (1970). Collective Choice and Social Welfare. Holden-Day.

Sen, A. (1976). Famines as Failures of Exchange Entitlements. Economic and Political Weekly, 11, 1273-1280.

Silverman, B. W. (1986). Density Estimation for Statistics and Data Analysis. London: Chapman and Hall. https://doi.org/10.1007/978-1-4899-3324-9.

Stiglitz, J. E., Sen, A., \& Fitoussi, J. P. (2009). Report by the Commission on the Measurement of Economic Performance and Social Progress. Report of the Commission on the Measurement of Economic Performance and Social Progress (CMEPSP).

Thomson, W. (2001). On the Axiomatic Method and Its Recent Applications to Game Theory and Resource Allocation. Social Choice and Welfare, 18, 327-386. https://doi.org/10.1007/s003550100106.

Wolter, K. M. (1985). Introduction to Variance Estimation. New York: Springer-Verlag.

\section{Copyrights}

Copyright for this article is retained by the author(s), with first publication rights granted to the journal.

This is an open-access article distributed under the terms and conditions of the Creative Commons Attribution license (http://creativecommons.org/licenses/by/4.0/). 